\title{
Receipt of Disability Benefits and Prescription Opioid Prevalence
}

\author{
Robin Ghertner, MPP(i)
}

$\mathrm{J}$ Gen Intern Med 36(2):557-8

DOI: $10.1007 / \mathrm{s} 11606-020-05685-6$

(c) Society of General Internal Medicine (This is a U.S. government work and not under copyright protection in the U.S.; foreign copyright protection may apply) 2020

\section{INTRODUCTION}

The availability of prescription opioids is a key factor in the opioid epidemic, where their misuse can lead to opioid use disorder (OUD). Compared with the general population, persons with disabilities are prescribed medications more frequent$1 y^{1}$ and may be more likely to misuse prescriptions. ${ }^{2}$ Temporarily disabled workers may experience longer periods of disability in areas with longer-term opioid prescribing. ${ }^{3}$ Recipients of social security disability insurance (SSDI) are more likely to have an opioid prescription than the general population. ${ }^{4}$ Among other factors, increased access to health insurance accompanying disability benefits could make recipients more vulnerable to overprescribing of opioids, which in turn could lead to greater incidence of OUD and opioid-related deaths. ${ }^{5,6}$

This study quantifies how the cumulative county-level change in opioid prescribing is explained by the change in receipt of SSDI and supplemental security income (SSI). SSDI and SSI differ substantively in their benefit structures and their beneficiary populations. For example, SSDI recipients are eligible for Medicare and SSI recipients are eligible for Medicaid. SSDI income is based on earned benefits through employment, while SSI income targets eligible low-income individuals. The study focuses on two periods before and after the national peak in opioid prescribing (2006-2012, 2012-2017).

\section{METHODS}

County prescribing rates were modeled for the general population, and for Medicare Part D recipients, using populationweighted linear regression models. The main independent variables were the county-level change in SSDI and SSI receipt rates. The number of general opioid prescriptions is from the IQVIA Xponent database, and Medicare Part D prescriptions are from records at the Centers for Medicare and Medicaid Services, both measured per 100,000 residents. Data on SSDI

Received January 9, 2020

Accepted January 26, 2020

Published online February 10, 2020 and SSI receipt come from the Social Security Administration. SSI data were restricted to adults receiving SSI due to a disability. SSDI and SSI recipiency is measured as the number of recipients per 100,000 adults aged 18 to 65 . Separate models were run for each opioid measure and benefit program.

Models accounted for confounding county characteristics including population, age and racial/ethnic makeup, median income, poverty, unemployment, and uninsurance rates, primary care physicians per capita, disabled and non-disabled Medicare beneficiaries, workplace injuries, and the relative size of major industries. To account for different state Medicaid opioid policies, models include the proportion of all state Medicaid prescriptions that are for an opioid.

The sample for SSDI models ranged from 2618 to 3043 U.S. counties, and the sample for SSI models ranged from 2353 to 2519 counties, depending on the model.

\section{RESULTS}

Figure 1 reports how much of county changes in opioid prescribing is explained by changes in disability benefits receipt. Over the 2006-2012 period, changes in SSDI receipt explained $28.07 \%$ of the change in opioid prescribing among a county's general population $(95 \% \mathrm{CI}=15.46 \%, 40.68 \% p=$ 0.000 ), and $35.94 \%$ of prescribing among the population receiving Medicare Part D (95\% CI $=27.04 \%, 44.84 \%, p=$ 0.000 ). Over the 2012-2017 period, SSDI changes explained $45.52 \%$ of general opioid prescribing $(95 \% \mathrm{CI}=29.42 \%$, $61.62 \%, p=0.000)$ and $70.32 \%$ of Medicare Part D prescribing $(95 \% \mathrm{CI}=53.72 \%, 86.1 \%, p=0.000)$.

SSI changes had an insignificant or negative relationship with general opioid prescribing. From 2012 to 2017, the estimated relationship is $-12.44 \%(95 \% \mathrm{CI}=22.02 \%$, $2.87 \%, p=0.000$ ). SSI changes had a positive relationship with Medicare Part D opioid prescribing, explaining 14.88\% $(95 \% \mathrm{CI}=5.47 \%, 24.30 \%, p=0.000)$ from 2006 to 2012 and $16.64 \%(95 \% \mathrm{CI}=5.06 \%, 28.22 \%, p=0.000)$ from 2012 to 2017.

\section{DISCUSSION}

The cumulative change in the receipt of disability benefits explains a significant amount of changes in opioid prescribing over two periods of time. Changes in SSI receipt had no 


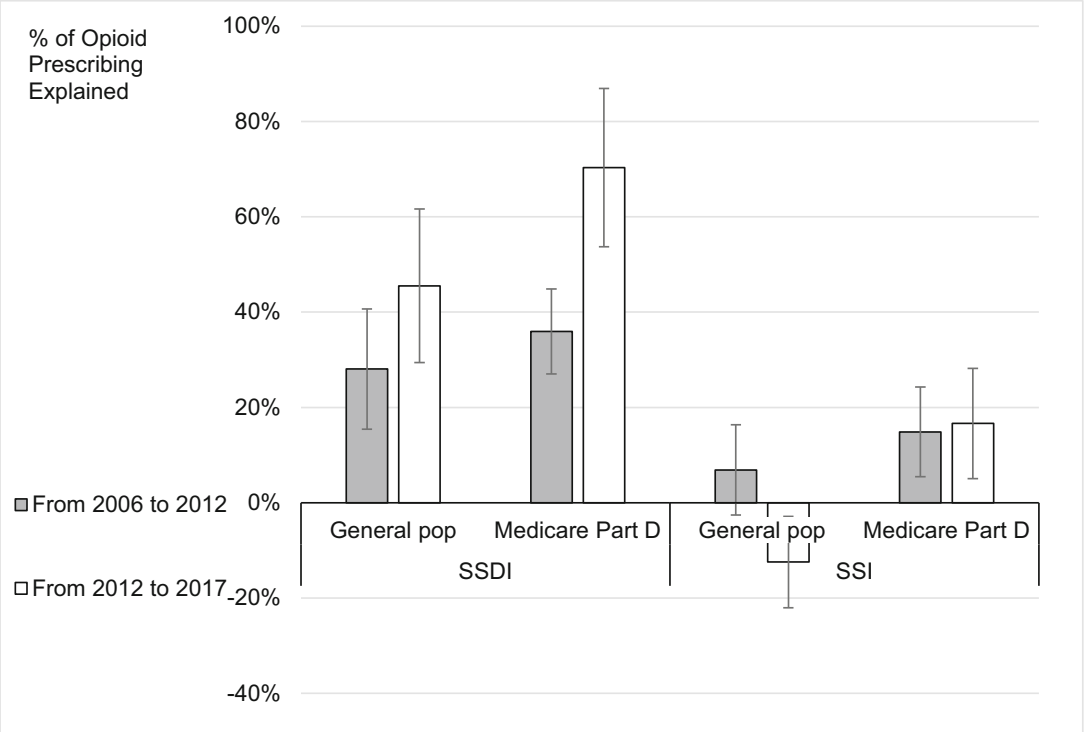

Figure 1 Percentage of Changes in Opioid Prescribing Explained by Changes in Federal Disability Benefits Receipt, $2006-2012$ and $2012-2017$. Note: Each estimate derived from separate regression models. $95 \%$ cluster-robust confidence intervals in parenthesis. $N:$ SSDI, general pop $=$ 2618; SSDI Med part $D=3043$; SSI, general pop=2353; SSI, Med part $D=2519$.

identifiable relationship with general opioid prescribing from 2006 to 2012 and had a negative relationship from 2012 to 2017, suggesting another underlying process mediated this relationship.

This study faces several limitations. The data do not permit identifying which disability beneficiaries receive prescription opioids. It is not possible to verify whether the type of disability beneficiaries have is related to the need for opioids. Also, the findings are not causal and should not be interpreted to mean that disability receipt caused changes in opioid prescribing.

As stakeholders seek to mitigate the current opioid crisis and avoid future ones, it is important to recognize the risk faced by disability benefit recipients. More work is needed to understand why changes in disability benefits predict prescribing patterns, and what factors underlie both phenomena.

Acknowledgments: The CMS Prescription Drug Event data extract was provided by Acumen, LLC, under contract with the Centers for Medicare and Medicaid Services, U.S. Department of Health and Human Services (Contract No. HHSM-500-2014-00027I; Task Order No. HHSM-500-T0004), with funding from the U.S. Department of Health and Human Services, Office of the Assistant Secretary for Planning and Evaluation. The author would like to thank Mir Ali and Judy Dey for their helpful comments on this manuscript.
Corresponding Author: Robin Ghertner, MPP; U.S. Department of Health and Human Services, Washington, DC, USA (e-mail: robinghertner@gmail.com).

\section{Compliance with Ethical Standards:}

Conflict of Interest: The author has no conflicts of interest to report.

\section{REFERENCES}

1. Stover BD, Turner JA, Franklin G, et al. Factors Associated With Early Opioid Prescription Among Workers With Low Back Injuries. J Pain. 2006;7(10):718-725. https://doi.org/10.1016/j.jpain.2006.03.004

2. Ford JA, Hinojosa MS, Nicholson HL. Disability status and prescription drug misuse among U.S. adults. Addict Behav. 2018;85:64-69. https:// doi.org/10.1016/j.addbeh.2018.05.019

3. Savych B, Neumark D, Lea R. Do Opioids Help Injured Workers Recover and Get Back to Work? The Impact of Opioid Prescriptions on Duration of Temporary Disability. Natl Bur Econ Res; 2018. https://doi.org/10.3386/ w24528

4. Gebauer S, Salas J, Scherrer JF, Burge S, Schneider FD. Disability Benefits and Change in Prescription Opioid Dose. Popul Health Manag. 2019;22(6):503-510. https://doi.org/10.1089/pop.2018.0210

5. King NB, Strumpf E, Harper S. Has the Increase in Disability Insurance Participation Contributed to Increased Opioid-Related Mortality? Ann Intern Med. 2016;165(10):729. https://doi.org/10.7326/M16-0918

6. CEA. The Role of Opioid Prices in the Evolving Opioid Crisis. Washington, DC: Council of Economic Advisors; 2019.

Publisher's Note Springer Nature remains neutral with regard to jurisdictional claims in published maps and institutional affiliations. 